\title{
Pesquisa Crítica de Colaboração: o ensino de Língua Portuguesa pensado com os surdos para os surdos
}

\author{
Maly Magalhães Freitas ${ }^{1}$ \\ Sueli Salles Fidalgo ${ }^{2}$ \\ Claudia Regina Vieira ${ }^{3}$
}

\begin{abstract}
RESUMO
Este estudo, recorte de uma pesquisa de doutorado finalizada, objetivou compreender as possibilidades de ensino-aprendizagem de aspectos gramaticais da língua portuguesa para surdos que já tenham experiência com essa língua. Apoiou-se na teoria Histórico-Cultural (VYGOTSKY 1924 - 1934), e em autores que discutem o ensino-aprendizagem do português para surdos (PEREIRA, 2009; LODI, et al., 2015; VIEIRA, 2014; 2017). Está inserido na Pesquisa Crítica de Colaboração - PCCol (MAGALHÃES, 2006; FIDALGO, 2006, MAGALHÃES; FIDALGO, 2019) porque se baseia na negociação de sentidos e significados, possibilitando reflexão e transformação dos participantes. Os dados foram produzidos em um curso à distancia onde os participantes, ao concluírem, puderam expor suas impressões e sugestões sobre o curso. As análises revelaram que as possibilidades de ensino-aprendizagem do português para surdos perpassam por estratégias visuais de ensino que contemplem a Libras como língua mediadora em todas as etapas do ensino-aprendizagem.
\end{abstract}

PALAVRAS-CHAVE: Surdos. Português para surdos. Educação de surdos. Teoria Histórico-Cultural. Pesquisa Crítica de Colaboração.

\footnotetext{
${ }^{1}$ Doutora em Ciências. Professora do Instituto Federal de São Paulo. Orcid: https://orcid.org/0000-0001-6795-0543. E-mail: malymfreitas@ifsp.edu.br.

${ }^{2}$ Doutora em Linguística Aplicada e Estudos da Linguagem. Professora da Universidade Federal de São Paulo. Orcid: https://orcid.org/0000-0001-6533-2346. E-mail: ssfidalgo@unifesp.br.

${ }^{3}$ Doutora em Educação. Professora da Universidade Federal do ABC. Orcid: https://orcid.org/0000-0002-5897-9122.

E-mail: claudia.vieira@ufabc.edu.br.
} 
Critical Collaboration Research: Portuguese language teaching thought with the deaf for the deaf

\begin{abstract}
This study, part of a completed doctoral research, aimed to understand the teaching-learning possibilities of grammatical aspects of the Portuguese language for deaf people who already have experience with this language. It was supported by the HistoricalCultural theory (VYGOTSKY 1924 - 1934), and by authors who discuss the teaching and learning of Portuguese for the deaf (PEREIRA, 2009; LODI, et al., 2015; VIEIRA, 2014; 2017). It is inserted in the Critical Collaboration Research - PCCol (MAGALHÃES, 2006; FIDALGO, 2006, MAGALHÃES; FIDALGO, 2019) because it is based on the negotiation of meanings, allowing reflection and transformation of the participants. The data were produced in a distance course where the participants, when they concluded, were able to expose their impressions and suggestions about the course. The analyzes revealed that the possibilities of teaching and learning Portuguese for the deaf go through visual teaching strategies that include Libras as a mediating language in all stages of teaching and learning.
\end{abstract}

KEYWORDS: Deaf. Portuguese for the deaf. Education of the deaf. Historical-Cultural Theory. Critical Collaborative Research.

Investigación de colaboración crítica: enseñanza de la lengua portuguesa con sordos a sordos

\title{
RESUMEN
}

Este estudio, que forma parte de una investigación doctoral finalizada, tuvo como objetivo comprender las posibilidades de enseñanza-aprendizaje de los aspectos gramaticales de la lengua portuguesa para las personas sordas que ya tienen experiencia con esta lengua. Fue apoyado por la teoría Histórico-Cultural (VYGOTSKY 1924 - 1934), y por autores que discuten la enseñanza y el aprendizaje del portugués para sordos (PEREIRA, 2009; LODI, et al., 2015; VIEIRA, 2014; 2017). Se inserta en la Investigación de Colaboración Crítica - PCCol (MAGALHÃES, 2006; FIDALGO, 2006, 
MAGALHÃES; FIDALGO, 2019) porque se basa en la negociación de significados, permitiendo la reflexión y transformación de los participantes. Los datos se produjeron en un curso a distancia donde los participantes, al finalizar, pudieron exponer sus impresiones y sugerencias sobre el curso. Los análisis revelaron que las posibilidades de enseñar y aprender portugués para sordos pasan por estrategias de enseñanza visual que incluyen a Libras como lengua mediadora en todas las etapas de la enseñanza y el aprendizaje.

PALABRAS CLAVE: Sordo. Portugués para sordos. Educación de sordos. Teoría Histórico-Cultural. Investigación Colaborativa Crítica.

$$
* * *
$$

\section{Introdução}

Discutir as questões que envolvem o ensino-aprendizagem da leitura e da escrita para surdos brasileiros, levando em consideração as concepções de língua que embasam as metodologias de ensino no país é importante para entender como hoje se dão as práticas de letramento de surdos. É preciso que tenhamos referência de como isso aconteceu no passado, porque os processos de ensino-aprendizagem - no caso, de língua portuguesa para surdos - que ocorriam anteriormente têm forte influência nos processos que ocorrem atualmente.

Durante mais de cem anos, as línguas de sinais foram proibidas no contexto escolar em nível mundial e, no Brasil não foi diferente: priorizou-se o ensino da língua portuguesa na modalidade oral com o objetivo de que os surdos se aproximassem ao máximo do padrão de normalidade ouvinte. Essa abordagem denomina-se oralismo. Na abordagem oralista, o ensino de leitura e escrita da língua portuguesa baseia-se em métodos tradicionais e na concepção de língua como um código - como ocorre com os ouvintes. Nessa concepção, a língua é ensinada por meio de estruturas frasais que vão das simples às mais complexas, valorizando-se principalmente a memorização de vocábulos como se costumava fazer (e, em alguns lugares ainda se faz) com o 
ensino de línguas estrangeiras e segundas línguas orais, por meio de métodos e abordagens como o método audiolingual, por exemplo. Em salas de aula que utilizam abordagens assim, as práticas pedagógicas são baseadas na repetição, na cópia, na reprodução, em exercícios mecânicos e descontextualizados. Para se chegar à aprendizagem do texto, primeiro, o aluno deve aprender as unidades que compõem a língua: letras e suas pronúncias, sílabas, palavras, frases e texto, seguindo uma ordem crescente do que se convencionou ser um grau de complexidade. No entanto, devido à falta de contexto com que as letras e as sílabas são ensinadas, por exemplo, a prática mostrou (e continua mostrando) que o ensino assim se torna muito mais difícil e muitos alunos - mesmo os ouvintes - não conseguem sair das unidades pequenas para a formação de textos. Na leitura também há uma dificuldade grande, visto que os textos são adaptados pelo professor para chegar ao que ele acredita ser o nível linguístico do aluno. Geralmente, portanto, são textos curtos e complexos visto que os professores acabam por tirar sinais que, na realidade nos ajudam a compreender o que lemos, como as repetições e os sinônimos, por exemplo.

No caso específico do aluno surdo, no Brasil, até meados do século $\mathrm{XX}$, muitos métodos dentro da abordagem oralista foram utilizados, a maioria dos quais partia do princípio da Chave de Fitzgerald ${ }^{4}$ (embora não se tenha usado esse nome).

Quadro 1 - Chave de Fitzgerald

\begin{tabular}{|c|c|c|c|c|c|}
\hline $\begin{array}{l}\text { Sujeito } \\
\text { (quem? } \\
\text { o que?) }\end{array}$ & Verbo & $\begin{array}{c}\text { Objeto } \\
\text { direto e } \\
\text { indireto (o } \\
\text { que? de } \\
\text { quem? } \\
\text { para } \\
\text { quem? etc. }\end{array}$ & Onde? & $\begin{array}{l}\text { Outras orações ou } \\
\text { modificadores do } \\
\text { verbo principal } \\
\text { (para, de, como, } \\
\text { quantos, com que } \\
\text { frequência etc.) }\end{array}$ & Quando? \\
\hline
\end{tabular}

Fonte: PEREIRA [entre 2014 e 2019]

\footnotetext{
${ }^{4}$ A Chave Fitzgerald foi desenvolvida em 1926 por uma professora surda, Edith Fitzgerald.
} 
A chave, como nos mostra o quadro acima, contém seis colunas com interrogações referentes às partes da oração, "começando com as que se referem ao sujeito, depois ao verbo e, quando os alunos dominam estruturas com sujeito e verbo, são introduzidos os complementos, um por vez" (PEREIRA, 2009, p.15). Em outras palavras, os alunos deviam aprender da unidade lexical e gramatical para a unidade textual.

Assim, os estudantes tinham que organizar suas frases de acordo com a estrutura gramatical dada pelo quadro, memorizando-a e utilizando-a em outros contextos linguísticos e discursivos. Segundo essa lógica, basta que o aluno substitua um elemento por outro na frase, repetindo a sua estrutura, para que alcance êxito na leitura, na escrita e na comunicação.

Apesar de alguns surdos conseguirem atingir o objetivo esperado para uso da língua, a grande maioria fracassava, como afirma Pereira (entre 2014 e 2019, p. 2)

Como resultado da concepção de língua e da ênfase na fala, embora alguns estudantes conseguissem atingir um bom nível no uso da Língua Portuguesa, a maior parte apresentava apenas estruturas fragmentadas da língua. Faltavam os elementos de ligação (preposições e conjunções), os verbos não eram flexionados e as palavras não seguiam a ordenação frasal da língua.

Devido ao fracasso educacional do oralismo e suas sérias consequências para o desenvolvimento dos surdos, que não atingiam o nível esperado para a aprendizagem, bem como aos movimentos sociais das comunidades surdas em prol da liberdade de uso da Libras, a abordagem da comunicação total começou a entrar nas salas de aula ( no Brasil, por volta dos anos 80) e o uso simultâneo de qualquer forma de comunicação - como os sinais da Libras, mímicas e o alfabeto manual - começou a ser aceito, juntamente com a oralização. No Brasil, utilizamos principalmente o 
português sinalizado (PS) ${ }^{5}$, i.e., o léxico da língua de sinais e/ou sinais inventados na estrutura gramatical da LP.

Entretanto, nessa abordagem, eram utilizados apenas fragmentos da língua de sinais (ou seja, sinais da língua de sinais, mas desconsiderando sua estrutura e gramática) com o objetivo de ensinar a língua portuguesa para os surdos e, também, de facilitar a comunicação entre surdos e ouvintes.

Os sinais da Libras e outros recursos espaço-visuais foram inseridos no contexto de comunicação, de ensino e de aprendizagem, mas os métodos de ensino continuaram sendo baseados na concepção de língua como código e nos métodos tradicionais. Os surdos continuaram à margem do processo educativo e não alcançaram êxito na leitura ou na escrita da língua portuguesa (LP), ou seja, o quadro de fracasso educacional do oralismo não foi alterado com a inclusão de outros recursos espaço-visuais na comunicação total.

Em consequência desses fatos e dos resultados das pesquisas de Willian Stokoe na década de 60 do século passado, que indicaram que as línguas de sinais são verdadeiramente línguas, iniciou-se um movimento em prol do bilinguismo ${ }^{6}$ dos surdos. Assim, as línguas de sinais passaram a ser consideradas como essenciais ao desenvolvimento do surdo, e começaram a ser divulgadas nos meios sociais. Entretanto, algumas pesquisas ${ }^{7}$ apontam que, dentro das escolas, os professores de surdos ainda encontram dificuldades em aprendê-las e usá-las com fluência devido, principalmente, a falhas na formação docente. Conforme afirma Giordani (2015, p. 144), há um faz de conta de que a Libras é usada na escola como primeira língua, pois os professores a conhecem muito pouco e simplificam seu uso; a equipe escolar a desconhece ou não tem acesso a ela. Todo esse histórico, claro, teve e tem impacto direto nas práticas pedagógicas utilizadas para o ensino dos surdos.

\footnotetext{
${ }^{5} \mathrm{O}$ conceito de português sinalizado será mais discutido mais adiante.

${ }^{6}$ Para saber mais sobre bilinguismo dos surdos, ver Skliar (1999) e Lodi, Melo e Fernandes (2015).

${ }^{7}$ Ver Vieira (2014), Góes (1996), entre outros.
} 
Nesse percurso, as pesquisas sobre alfabetização e letramento também se ampliaram e começamos a discutir a concepção de língua não mais como código, mas como interacional e dialógica ${ }^{8}$. Sob esta concepção, as unidades de ensino deixam de ser as letras e as sílabas e passam a ser o texto. O texto, então, é compreendido como fonte de prática discursiva, e a gramática, segundo esta concepção, deve ser aprendida no uso dos gêneros textuais, ou seja, dentro de um contexto.

$\mathrm{Na}$ área da educação de surdos, também intensificamos as pesquisas, muitas delas acerca do ensino-aprendizagem de português como segunda língua. Isso ocorreu principalmente a partir do reconhecimento da Libras como língua do surdo, por meio da lei $\mathrm{n}^{\circ}$ 10.436/2002 (BRASIL, 2002) e de sua regulamentação através do decreto $n^{0}$ 5626/2005 (BRASIL, 2005). Com essa legislação, a Libras começou a ser divulgada na sociedade de um modo geral, e nas escolas o seu uso passou a ser obrigatório - mesmo que de modo restrito - quando há surdos inseridos em contextos educacionais.

Diante desses movimentos de mudança de concepção de língua, reconhecimento das línguas de sinais como línguas, da Libras como língua do surdo brasileiro, da inserção dessa língua nos espaços educacionais, sociais etc., esperávamos um melhor resultado na qualidade da educação dos surdos. Entretanto, não é o que as pesquisas indicam. Ao contrário, têm mostrado que ainda baseamos nossas práticas de ensino de língua portuguesa para surdos em uma concepção de língua como código, em métodos tradicionais de ensino, valorizando principalmente o conhecimento sistêmico, ou seja, do vocabulário e da gramática como garantia de que o aluno lê e escreve bem. Além disso, a escrita ainda é vista como representação da oralidade: para o ouvinte, a relação fonema/grafema; para o surdo, a relação letra/alfabeto manual.

\footnotetext{
${ }^{8}$ Com base em Bakhtin (1953), Koch (2011, p. 17) discute que, na concepção interacional e dialógica de língua, os sujeitos são percebidos como construtores sociais, o texto é o lugar de interação e os interlocutores são sujeitos ativos que nele se constroem e são construídos. Nesta concepção, segundo a autora, "sentido do texto é, portanto, construído na interação texto-sujeitos (ou texto-co-enunciadores) e não algo que preexista a essa interação".
} 
No caso do alfabeto manual, trata-se de uma representação das letras do português9; já no caso do vocabulário, tenta-se fazer equivalência das palavras do português, das letras que as compõem com algum sinal da Libras acreditando-se, em ambos os casos, ser possível uma relação biunívoca entre as línguas. Isto significa que ainda tropeçamos em práticas baseadas na comunicação total com uso predominante do português sinalizado tanto na comunicação como em estratégias de ensino da leitura e da escrita. O PS é caracterizado pela

[...] utilização dos sinais extraídos da LIBRAS (Língua Brasileira de Sinais), inseridos à estrutura da língua portuguesa, a língua majoritária. Como não existem na língua de sinais certos componentes da estrutura frasal do português (preposição, conjunção etc.), são criados sinais para expressá-los. Além disso, utiliza-se marcadores de tempo, número e gênero para descrever a língua portuguesa através de sinais (DORZIAT, 1997, p. 305).

Ele foi muito utilizado na abordagem da Comunicação Total (CT) como recurso facilitador da comunicação, entretanto, o PS ou "os sistemas orais sinalizados, como se sabe, não correspondem a línguas de sinais: têm a superestrutura da língua oral considerada, e emprestam o léxico da língua de sinais do país em questão de modo mais ou menos sistemático" (SOUZA, 2003, p. 338), i.e., uma espécie de sobreposição de uma língua oral a outra língua de modalidade espaço-visual. Além disso, o português sinalizado não contempla a visualidade - entendida aqui não como o que se pode ver, pois isso seria possível tanto no PS quanto no português escrito, mas como o todo da gramática da Libras, ou seja, a visualidade que compõe o enunciado -, já que carrega a estrutura gramatical da LP, que é oral-auditiva. Um exemplo disso é a tradução da frase em português "O carro bateu na árvore". Em português sinalizado, teríamos a seguinte estrutura:

\footnotetext{
${ }^{9}$ Em 30 de novembro 1949, a Associação Nacional dos Surdos publicou na revista do Instituto Nacional de Surdos-Mudos a afirmação de que "O alfabeto digital é, realmente, a escrita ou soletração no ar "(sem paginação). Na página consta a data de 03.11.1949, podendo ser um erro de gráfica. Já naquela época, o alfabeto era percebido como representação da LP escrita. Disponível em: http://repositorio.ines.gov.br/ilustra/handle/123456789/378. Acesso em 14 maio 2020.
} 
Imagem 1 - Exemplo de frase em OS

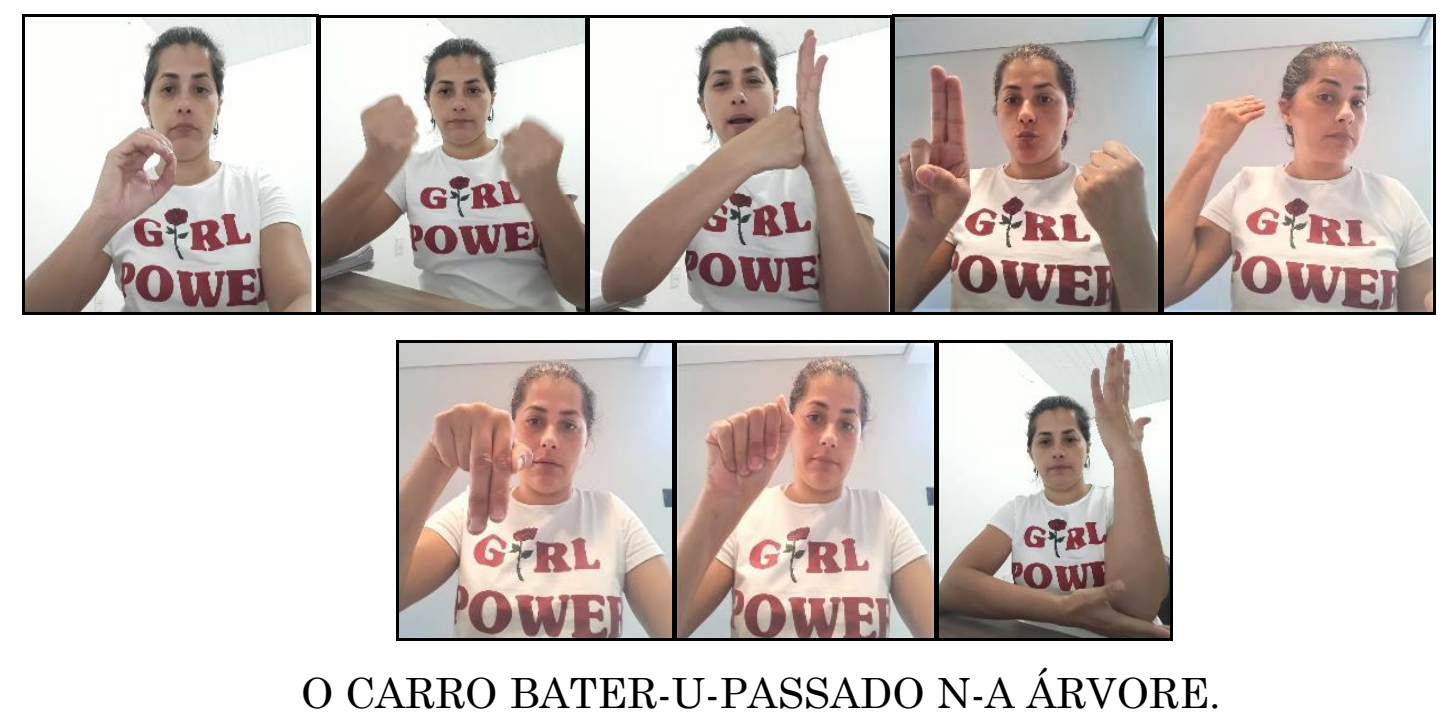

Fonte: Freitas (2020, p. 112)

Para cada palavra do português, temos um sinal respectivo, mas obedecendo à estrutura gramatical da língua oral. Assim, apesar de "vermos" os sinais, a estrutura da LP não permite, entre outros aspectos, a simultaneidade própria das línguas de sinais, que favorece a significação através da visualidade do enunciado. Destacamos, ainda, conforme Vieira (2017), que:

Essa prática foi nomeada bimodalismo, pois trabalha com a utilização de duas modalidades de línguas diferentes, nesse caso específico, oral e visual, e leva a crer que exista uma correspondência entre sinal e palavra, o que descaracteriza a Língua de Sinais como língua considerando-a exclusivamente como representação da língua majoritária (VIEIRA, 2017, p.64).

Este - o PS - não foi desenvolvido pela comunidade que a utilizava (os surdos) de forma colaborativa e na medida em que apareciam as necessidades, como ocorre com todas as línguas. Trazia algumas crenças e sentidos dos surdos, mas não a totalidade que se verifica em uma língua com signos arbitrária e coletivamente construídos.

Em Libras, essa frase poderia ser traduzida da seguinte maneira: 
Imagem 2 - Exemplo de frase em Libras

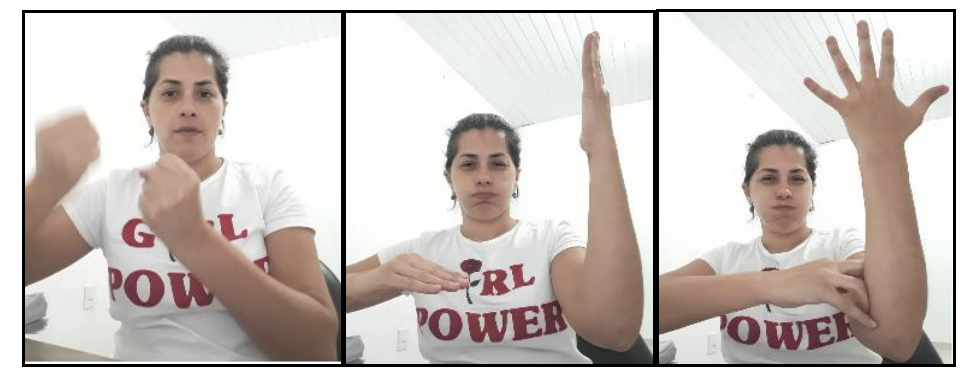

CARRO ÁRVORE BATER.

Fonte: Freitas (2020, p. 113)

$\mathrm{Na}$ estrutura da Libras, temos o sinal de carro, um classificador ${ }^{10}$ (CL) de carro e o sinal de árvore, simultaneamente, e o carro movimentandose em direção à árvore até colidir contra ela, acompanhados de expressão facial e corporal. Podemos observar, então, a visualidade no enunciado, que é intrínseca a esta modalidade linguística.

É importante ressaltar que, apesar de essa ainda ser uma realidade na maioria das escolas, temos que reconhecer que já há algumas iniciativas de mudança nas práticas de alguns professores, em busca de uma educação bilíngue ${ }^{11}$.

Desse modo, consideramos importante investigar quais as principais dificuldades que os surdos encontram no ensino-aprendizagem de alguns aspectos da língua portuguesa.

\section{Metodologia}

Este estudo tem como base metodológica os pressupostos da Pesquisa crítica de colaboração (PCCol), pois a reflexão sobre os instrumentos de ensino-aprendizagem, a metodologia de ensino, o conteúdo e os recursos didáticos foram feitos por todos os envolvidos -

\footnotetext{
${ }^{10}$ Classificadores em Libras, segundo Felipe (2007, p. 172), "são configurações de mãos que, relacionadas à coisa, pessoa, animal e veículo, funcionam como marcadores de concordância. Assim, na Libras, os classificadores são formas que, substituindo o nome que as precedem, podem ser presas à raiz verbal para classificar o sujeito ou o objeto que está ligado à ação do verbo. Portanto, os classificadores na Libras são marcadores de concordância de gênero".

11 No Brasil, há uma multiplicidade de compreensões sobre o que é bilinguismo para surdos, e isto impacta diretamente nas práticas de ensino. Não há um consenso, e talvez isso não seja almejado, visto que as escolas são compostas por diferentes culturas, histórias, experiências e concepções.
} 
participantes surdos juntamente com a pesquisadora. $\mathrm{Na}$ pesquisa colaborativa, todos são participantes, inclusive a pesquisadora, na produção do conhecimento, o que envolve suporte, assistência na reflexão e reinterpretação coletiva da ação. Segundo Fidalgo (2006, p. XVIII; 2018, p.37),

Esta nova forma de produzir conhecimento implica em ouvir as vozes de todos os envolvidos em uma pesquisa [...] para construir conhecimento conjuntamente, considerando, ao longo do trabalho, entre outros aspectos, 'o tipo de conhecimento produzido, o contexto de produção, a responsabilidade social e a reflexão'.

Assim, todos têm as mesmas oportunidades de apresentar suas opiniões e pontos de vista sobre a realidade na qual estão inseridos, de escolherem os temas ou "problemas" a serem discutidos. Neste tipo de pesquisa, então, a hierarquia entre os participantes (inevitável pois sempre haverá um pesquisador que, entre outros aspectos, é o responsável pelo relatório final do trabalho) é menor e minimizada ao máximo, dando vez à consideração de que todos têm potencialidades para colaborar nas discussões e na pesquisa com seus conhecimentos, opiniões, crenças, valores, experiências etc.

Seguindo esta matriz metodológica, a pesquisa foi desenvolvida de maneira colaborativa, pois todos os sujeitos, pesquisadora e participantes surdos, foram ativos na busca de respostas às inquietações que deram origem ao estudo. Ainda conforme Fidalgo (2006, p.25), discutindo Magalhães (1994, p.72), vale lembrar que:

[...] este tipo de pesquisa considera o outro como parte do processo investigativo e não apenas como objeto para coleta ou análise de dados, procura negociar com ele os instrumentos, as práticas de busca e, sempre que possível, o que supostamente teria sido encontrado, evitando, assim, conclusões unilaterais.

Isso não significa que o processo colaborativo comporte apenas semelhança de ideias e concordância nas discussões. Ao contrário, colaborar 
só é possível a partir de conflitos, confronto de ideias, questionamentos e tensões. É importante lembrar que, sempre que um interlocutor não compreende o que está sendo dito e faz uma pergunta, está estabelecido um conflito. Na PCCol, o termo conflito não é, portanto, negativo. É o que possibilita aos participantes repensarem suas falas e negociarem sentidos para que novos conhecimentos sejam construídos.

Além disso, entre os participantes, há diferentes histórias de vida, crenças, valores, culturas e esta diversidade de experiências e visões de mundo pode trazer à tona confrontos de ideias, que acarretam conflitos (leiase: questionamentos, dúvidas) tanto interpessoais quanto intrapessoais. O conflito faz parte de qualquer aprendizado, mais do que isso, ele é imprescindível para que o aprendizado ocorra. Schön (1992), por exemplo, afirma que não existe aprendizagem sem conflito. Então, o confronto de ideias e os conflitos - interpessoal e intrapessoal - favorecem o aprendizado, permitem que conhecimentos sejam construídos pois são eles que impulsionam para a negociação e ressignificação de sentidos. Assim, as interpretações de todos os participantes sobre o tema discutido (ação pedagógica ou mesmo as teorias de ensino-aprendizagem) são debatidas em suas semelhanças e diferenças.

Para a produção de dados desta pesquisa desenvolvemos um curso à distância sobre alguns aspectos gramaticais da língua portuguesa, pautados no novo acordo ortográfico, utilizando a plataforma moodle para disponibilização do mesmo. Participaram da pesquisa quatro surdos com nível superior de ensino, além da professora-pesquisadora. Para o primeiro modelo oferecido (etapa 1), o curso foi dividido em 4 módulos sobre os seguintes assuntos: trema, acentuação gráfica, hífen e crase, e uso dos porquês. Cada módulo contém uma videoaula explicando as regras ortográficas da língua portuguesa em Libras e fornecendo exemplos seguidos de atividades, fórum de discussão (FD), onde os participantes poderiam tirar dúvidas e avaliar o curso em relação as dificuldades e poderiam dar sugestões para resolvê-las. Fizemos também 
encontros virtuais para o que chamamos de conversa reflexiva12 $(\mathrm{CR})$, onde participantes e pesquisadora puderam refletir mais profundamente sobre o que foi posto no fórum. A partir dessa conversa, o módulo crase foi reformulado (etapa 2) considerando as sugestões dos participantes e eles o refizeram e reavaliaram.

A análise dos dados foi feita usando conteúdo temático (BRONCKART, 1999) e significação (VYGOTSKY, [1934] 2001). Conteúdo temático, segundo Bronckart (1999, p. 97), é o conjunto das informações explicitamente apresentadas no texto e que foram construídas pelos participantes através do conhecimento originado nos mundos formais ${ }^{13}$. A análise do conteúdo temático está embasada nas CRs e na participação dos estudantes no FD do curso. Os quadros de conteúdos temáticos são divididos em três colunas. Como faz Fidalgo (2006), em seu trabalho, na primeira coluna, foi incluído o tema - em forma normalizada do que o participante disse -; na segunda coluna, a interpretação (ou o sentido que compreendo como explícito na fala dos participantes), e na última coluna, a pergunta feita e a resposta do participante ${ }^{14}$. Embora Vygotsky ([1934] 2001) tenha usado os termos sentido e significado, as leituras mais atuais da obra do autor indicam que esses termos, assim separados, podem levar a uma visão dicotômica - o que não era adotado em seus trabalhos. Desse modo utilizamos o conceito de significação, conforme explicitado por Aguiar e Ozella (2006,2013). Assim, segundo Vygostky (idem) o significado se constrói coletivamente, enquanto o sentido é individual. Para ele, "uma palavra adquire seu sentido no contexto em que surge; em contextos diferentes,

\footnotetext{
${ }^{12}$ Chamamos de conversa reflexiva porque a discussao não seguia exatamente os passos de uma sessão reflexiva (MAGALHÃES, 2006, P.101) e nem o ciclo de reflexão critica proposto por Smyth (1992).

${ }^{13}$ Conforme o autor, são três os mundos formais: o mundo físico, que diz respeito às ações objetivas; o mundo social, que diz respeito às normas e regras a que os participantes se sujeitam ou que criticam; e o mundo subjetivo, que diz respeito ao que é internalizado, àquilo que apenas o participante tem acesso, por dizer respeito à sua subjetividade

${ }^{14}$ A transcrição das respostas dos participantes da Libras para o português e seguem normas de transcrição revista e adaptada de Felipe (2007), pelos grupos de pesquisa Inclusão Linguística em Cenários de Atividades Educacionais (ILCAE da Pontificia Universidade Católica (PUC-SP) e Grupo de Estudos sobre Identidade e Cultura Surda (GEICS) e Inclusão Social-Educacional e Formação (ISEF) da Universidade Federal de São Paulo (UNIFESP). A resposta sublinhada se refere ao trecho da fala que dá sentido ao que está na segunda coluna denominada "significação".
} 
altera seu sentido. O significado permanece estável ao longo de todas as alterações de sentido" (p.125).

\section{Discussão e análise dos dados}

Português sinalizado não é Libras

Uma das dificuldades apontadas pelos participantes em relação ao primeiro curso oferecido, foi o fato de que as explicações foram realizadas em português sinalizado (PS), o que dificultou a compreensão sobre o conteúdo. Essa dificuldade se deve ao fato de que, conforme explicado anteriormente, o PS não é composto de aspectos visuais como a Libras. Essa dificuldade pode ser percebida no quadro abaixo, retirado da conversa reflexiva com Mariana ${ }^{15}$ :

Quadro 2 - Dificuldades apontadas na CR sobre o primeiro modelo de curso

\begin{tabular}{|c|c|c|}
\hline Tema & Significação & Exemplo \\
\hline $\begin{array}{l}\text { Tipo de } \\
\text { dificuldade }\end{array}$ & $\begin{array}{l}\text { O português } \\
\text { sinalizado não } \\
\text { promove a } \\
\text { compreensão }\end{array}$ & $\begin{array}{l}\text { P29: EU LIBRAS CLARO-NÃO VOCÊ EXPLICAR } \\
\text { MELHOR ENTENDER EU COMO LIBRAS } \\
\text { MELHORAR DESENVOLVER “int” } \\
\text { M29: PORQUE VOCÊ EU PERCEBER VOCE } \\
\text { SEGUIR PORTUGUÊS EXEMPLO SLIDES IGUAL } \\
\text { SINAIS IGUAL EXEMPLO DIRIGIR CAMINHO } \\
\text { ENTENDER-NÃO CLARO-NÃO ENTENDER “int" } \\
\text { P30: [...] EXEMPLO AULA TER EXEMPLO FRASE } \\
\text { COMO USAR ACENTOS EXEMPLO SLIDES EU } \\
\text { SEGUIR PORTUGUES EXEMPLO OPINIÂO SUA } \\
\text { MOSTRAR OPINIÃO FRASES LIBRAS } \\
\text { DIFERENTE “int” } \\
\text { M30: EU ACHAR MELHOR DIFERENTE PORQUE } \\
\text { LIBRAS PRÓPRIO LIBRAS EXPLICAR LIBRAS } \\
\text { MOSTRAR PORTUGUÊS SURDO CONSEGUIR } \\
\text { ENTENDER LIBRAS SE SEGUIR PORTUGUÊS } \\
\text { PESADO COMO ENTENDER-NÃO SEQUÊNCIA /I }\end{array}$ \\
\hline
\end{tabular}

Fonte: Freitas (2020, p. 113)

Mariana explica que percebeu que a professora não estava falando em Libras quando dava os exemplos e que, por isso, teve dificuldades de

\footnotetext{
${ }^{15}$ Os nomes dos participantes são fictícios.
} 
entender o significado daquela frase. Ela diz que percebeu por que a sequência da sinalização estava idêntica ao que consta nos slides em português. Ela conclui dizendo que seguir o português, ou seja, usar o PS deixa o conteúdo pesado e dificulta a compreensão.

Isso ocorre porque o PS, como dito anteriormente, não se constitui como uma língua natural, mas sim como um sistema de comunicação. Conforme afirma o currículo de Língua Portuguesa para surdos do município de São Paulo (SÃO PAULO, 2019), os sistemas de comunicação não são línguas naturais, mas sim ferramentas criadas para comunicação entre as pessoas, os quais não podem ser analisados linguisticamente, pois não possuem estruturas presentes nas línguas naturais. Desse modo, o PS não possui a estrutura linguística necessária para explicar uma língua.

Mariana completa sua resposta no fórum de discussão, conforme quadro a seguir:

Quadro 3 - Dificuldades apontadas no FD do primeiro modelo de curso

\begin{tabular}{|l|l|l|}
\hline \multicolumn{1}{|c|}{ Tema } & \multicolumn{1}{|c|}{ Significação } & \multicolumn{1}{c|}{ Exemplo } \\
\hline $\begin{array}{l}\text { Tipo de } \\
\text { dificuldade }\end{array}$ & $\begin{array}{l}\text { A Libras não pode } \\
\text { ser substituída } \\
\text { pelo PS }\end{array}$ & $\begin{array}{l}\text { Mariana: “Não tem como substituir } \\
\text { Libras... Libras segue português, eu não } \\
\text { consegui entende...” }\end{array}$ \\
\hline
\end{tabular}

Fonte: Freitas (2020, p. 114)

Quando afirma que "não tem como substituir Libras", entendemos que ela quer dizer que cada língua tem sua própria estrutura gramatical; sendo assim, ao simplesmente substituir cada palavra por um sinal, automaticamente se privilegia a estrutura da língua majoritária - no caso, a língua oral. Isso significa que o PS "não utiliza a Libras como língua, mas seus sinais como ferramenta" (VIEIRA, 2017, p.69). Dessa forma, a compreensão fica comprometida. Por esse motivo, Mariana (M30) e Bruna (B2) sugerem que a Libras seja utilizada para explicar a LP, conforme observamos no quadro: 
Quadro 4 - Sugestões apontadas na CR sobre o primeiro modelo de curso

\begin{tabular}{|c|c|c|}
\hline Tema & Significação & Exemplo \\
\hline $\begin{array}{l}\text { Metodologia } \\
\text { que cria espaço } \\
\text { de } \\
\text { aprendizagem } \\
\text { de LP por } \\
\text { estudantes } \\
\text { surdos }\end{array}$ & $\begin{array}{l}\text { Uso de Libras } \\
\text { para explicar o } \\
\text { português; }\end{array}$ & 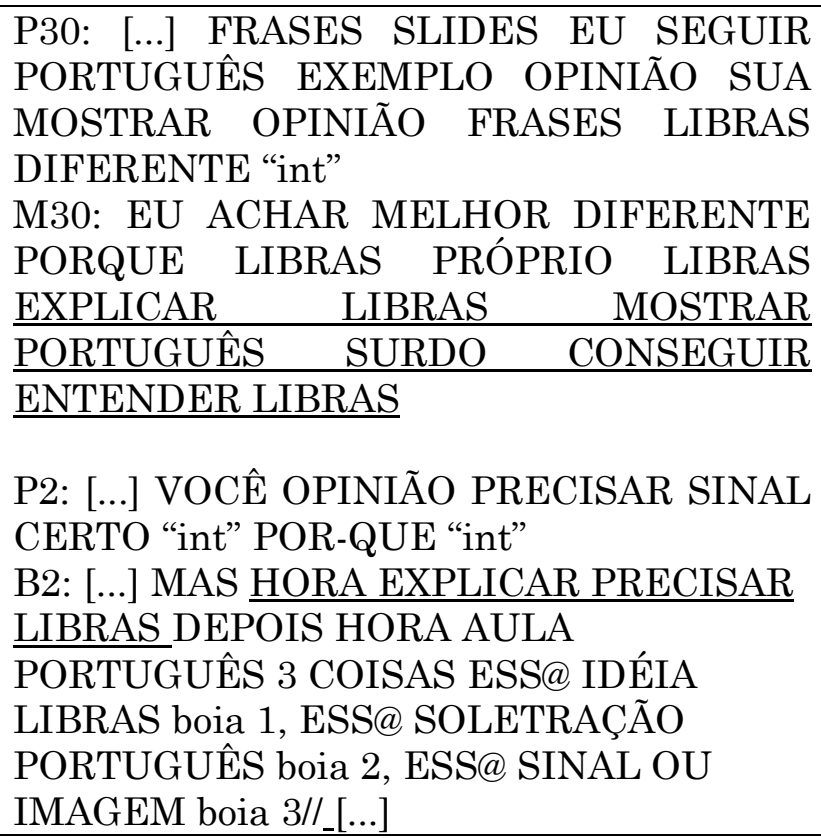 \\
\hline
\end{tabular}

Fonte: Freitas (2020, p. 116)

Mariana e Bruna afirmam que os surdos conseguem entender melhor quando a explicação se dá na Libras. Mariana complementa ainda que "libras mostrar português", i.e., que é através da Libras que o surdo pode visualizar a LP com clareza.

Moura (2015) pesquisou sua própria prática docente em relação ao ensino-aprendizagem de leitura de LP em uma escola do município de São Paulo que atende estudantes surdos na educação infantil e ensino fundamental, e teve como participantes os estudantes do $4^{\circ}$ ano do Ciclo I e a professora-pesquisadora. Foi analisada uma aula de leitura de LP como L2 e, como resultado, a autora afirma a importância da Libras como L1, sem a qual não há como ensinar a língua-alvo - no caso, o português na modalidade escrita. Ela também traz, na sua discussão, a Libras como mediadora do ensino-aprendizagem da LP. Como exemplo de análise de seus dados, a pesquisadora avaliou a leitura do trecho de um texto feito por duas alunas. Durante essa leitura, uma das alunas perguntou a ela o significado de uma determinada palavra que aparecia 
no texto. Ela as orientou a tentar inferir o significado da palavra dentro do texto, i.e., no contexto, e a não se prender apenas à palavra isolada. Ao fim, as alunas realizam a leitura proposta, e constatam que o contexto é importante para se compreender o que está sendo lido.

No caso dos surdos, isso ocorre quando a leitura consegue se desvencilhar da correspondência direta palavra-sinal e quando a Língua de Sinais passa a ser utilizada como mediadora na negociação de sentidos e significados (MOURA, 2015, p. 104).

Bruna, assim como Mariana, também sugere que a explicação deve ser dada em Libras, e que no momento de exemplificar a regra, seria melhor usar Libras + soletração + imagem. Dessa forma, o surdo tem mais chances de compreender por ter diversas possibilidades de acesso à informação. Essa sugestão é corroborada por Sofiato e Leão (2014) quando afirmam que,

Percebe-se que a hibridização ${ }^{16}$ de recursos pode facilitar o processo de compreensão de conceitos por parte do aluno surdo e proporcionar novas vivências a partir da contextualização dos mesmos (SOFIATO; LEÃO, 2014 p.03097).

Assim, quando os autores afirmam que a hibridização de recursos pode facilitar a aprendizagem dos estudantes surdos, isto significa que quanto mais caminhos com recursos diversos, principalmente visuais, forem oportunizados aos surdos, maiores serão as possibilidades de aprendizagem.

Temos, também, o decreto $\mathrm{n}^{0}$ 5626/2005 (BRASIL, 2005), marco regulamentador da lei $\mathrm{n}^{\circ}$ 10.436/2002 (BRASIL, 2002), que além de reconhecer a Libras como Língua da comunidade surda, afirma, no artigo 22 , incisos I e II, parágrafo $1^{\circ}$, que a Libras e a modalidade escrita da LP são as línguas de instrução na educação dos surdos. Assim, conforme quadro a seguir, a sugestão de utilizar a Libras para explicar e

\footnotetext{
${ }^{16}$ Hibridização de recursos pode ser compreendido como a " [...] versatilidade do suporte pictórico em relação às suas formas de apresentação, interdisciplinaridade e diferentes possibilidades de contribuição para o processo de ensino e aprendizagem [...] ." (SOFIATO; LEÃO, 2014, p.03097)
} 
exemplificar na reelaboração do curso foi aceita e o português sinalizado foi excluído do curso.

Quadro 5 - CR sobre o curso revisto

\begin{tabular}{|c|c|c|}
\hline Tema & Significação & Exemplo \\
\hline $\begin{array}{l}\text { Metodologias, } \\
\text { recursos e } \\
\text { instrumentos } \\
\text { que podem ser } \\
\text { utilizados para } \\
\text { resolver tais } \\
\text { dificuldades }\end{array}$ & $\begin{array}{l}\text { A explicação } \\
\text { dada em Libras, } \\
\text { a visualidade e a } \\
\text { apresentação de } \\
\text { vários exemplos } \\
\text { tornaram o } \\
\text { conteúdo muito } \\
\text { mais } \\
\text { compreensível }\end{array}$ & $\begin{array}{l}\text { P1: ANTES EXPLICAR CONTEXTO IMAGEM } \\
\text { CRASE LEMBRAR PERGUNTAR O-QUE } \\
\text { ANTES DIFICIL NOVO COMO “int" } \\
\text { M1: ANTES LIBRAS SEGUIR MUITO } \\
\text { PORTUGUẼS SEGUIR CONSEGUIR NÃO } \\
\text { ENTENDER-NÃO AGORA NOVO MUDAR } \\
\text { LIBRAS SÓ LIBRAS CONSEGUIR } \\
\text { ENTENDER TAMBÉM MELHOR VISUAL } \\
\text { QUADRADO LIBRAS QUADRADO LIBRAS } \\
\text { (CL) TAMBÉM MUITO MOSTRA EXEMPLOS } \\
\text { SEQUÊNCIA EXEMPLOS + OUTRO } \\
\text { ENTENDER ANTES EXEMPLO POUCO } \\
\text { AGORA MAIS EXEMPLOS COMPARAR } \\
\text { DIFERENTE MELHORAR. } \\
\text { P27: EXEMPLO EXPLICAR REGRA DEPOIS } \\
\text { EXEMPLOS PALAVRA ++ IMAGEM PALAVRA } \\
\text { IMAGEM (CL tabela) AJUDAR "int" } \\
\text { [...] } \\
\text { J29: SIM AS-VEZES USAR LIBRAS APOIO } \\
\text { ENSINAR PORTUGUES ENTENDER “int" } \\
\text { \#não é\# MAMÃE SEMPRE PALAVRA + } \\
\text { MOSTRAR TER-NÃO \#não tinha\# IMAGEM } \\
\text { PORQUE AS-VEZES EXEMPLO PALAVRA } \\
\text { MANGA AS-VEZES MOSTRAR IMAGEM } \\
\text { FRUTA OU BLUSA SÓ AJUDAR APOIAR } \\
\text { MAS DEPOIS FRASE EU PRECISAR } \\
\text { PERCEBER CONCEITO FRUTA OU BLUSA } \\
\text { P2.1: Nesse segundo vídeo não há português } \\
\text { sinalizado, somente Libras. } \\
\text { P2.2: sua opinião melhor Libras então? } \\
\text { S2: sim Libras, mas acho importante comparar } \\
\text { a estrutura das línguas, pois percebendo a } \\
\text { diferença entre a estrutura da Libras e a do } \\
\text { Português fica mais fácil de relacionar as } \\
\text { diferentes situações em que a crase ocorre. }\end{array}$ \\
\hline
\end{tabular}

Fonte: Freitas (2020, p. 119)

Mariana, João e Sérgio concordam que reelaboração do curso ficou muito mais compreensível com a exclusão do PS e a utilização somente da Libras tanto 
para explicar como para exemplificar ${ }^{17}$ o conteúdo do módulo que foi reformulado (crase). Assim, concordo com Vieira (2017) quando afirma que,

Sabemos, no entanto, que o surdo tem total condição de aprender, mas para isso deve viver experiências em L1, no caso a Libras. É ela que vai mediar o aprendizado da L2, Língua Portuguesa, porque é a Libras que estruturará o pensamento e então permitirá que os conteúdos sejam compreendidos e 'traduzidos' significativamente (VIEIRA, 2017, p. 96, grifo nosso).

Com esse entendimento, o PS não tem condições nem de explicar, nem de exemplificar a LP em situações de ensino-aprendizagem dessa língua pelos surdos, tanto em situações de escrita quanto de leitura. A única língua que pode cumprir esse papel para os surdos brasileiros é a Libras.

No curso revisto e reelaborado é a Libras que se utiliza para explicar e exemplificar, atendendo as sugestões de Mariana e Bruna. A tradução dos exemplos é feita com legendas em português, mostrando as diferenças entre as duas línguas.

Como os surdos se comunicam por meio da Língua de Sinais, o tratamento dos elementos gramaticais poderia ser construído com base na gramática contrastiva e discursiva de linguagem, por meio da qual os professores relacionariam os aspectos concernentes de ambas às línguas (PINHEIRO, 2020, p.380).

Dessa maneira, considerar a especificidade linguística dos surdos, bem como relacionar as línguas em questão, comparando-as e apontando suas semelhanças e diferenças - visto que a consciência metalinguística da L1 é que vai permitir a compreensão sobre o uso e funcionamento da L2 - mostrou ser um caminho possível para o ensino-aprendizagem do português também no ambiente virtual, da mesma forma que tem se mostrado para o ensino-aprendizagem presencial, ainda que o assunto estudado seja uma especificidade da L2 comumente considerado árido e de difícil compreensão mesmo para ouvintes.

\footnotetext{
${ }^{17}$ Junto com a exemplificação em Libras foi inserida legenda em português, mostrando o uso na língua-alvo.
} 


\section{Considerações finais}

De modo geral, as dificuldades que os participantes pontuaram estão localizadas no primeiro modelo oferecido e são mais relacionadas à metodologia e às estratégias utilizadas que, de certo modo, vão influenciar o conteúdo. Todos relataram entre outras, dificuldades no que diz respeito ao uso do português sinalizado, como se este conseguisse ter o mesmo efeito que o uso da língua de sinais. Entretanto, os estudos sobre essa questão indicam que há uma falsa sensação de que o uso do PS como língua abarca e preenche por si só o campo de estratégias visuais. Ao inserir recursos visuais aliados ao uso da Libras no curso revisto, os participantes relataram que houve maior compreensão dos conceitos por estes estarem acompanhados de exemplos que agregavam Libras + imagem + legenda em português.

A utilização do português sinalizado revelou que, apesar dos estudos e pesquisas sobre a Libras, ainda permanecem, na educação, práticas de ensino-aprendizagem - alicerçadas nas diferenças estruturais e de modalidade entre as línguas - que significam a língua de sinais como insuficiente para explicar a LP. A pesquisa mostrou justamente o contrário. O PS, por representar a LP com sinais, muitas vezes "aleatórios", não tem condições de explicar ou exemplificar nem o uso, nem a forma da LP, que é tão complexa quanto a de Libras. O PS não substitui nenhuma língua, nem a Libras nem a LP; assim, pode ser excluído como forma de comunicação e como mediador entre o surdo e a LP.

A fundamentação teórica na qual este estudo está ancorado nos permitiu refletir sobre as estratégias utilizadas, e que muitos professores ainda usam em sala de aula: o ensino-aprendizagem de L1 e L2 para surdos baseado em concepções de língua já ultrapassadas, as metodologias de ensino de L2/LE que, embora de forma não consciente/não refletida, tem forte influência nas práticas de sala de aula. 
Também nos permitiu confirmar que o essencial em ensino-aprendizagem é reconhecer a necessidade daquele que busca aprender. Em outras palavras, não importa o quão bem elaborado um professor pensa que está o seu curso, se este não faz sentido para o estudante, se causa dificuldade, é preciso que o planejamento seja refeito. E é necessário que o surdo tenha esse mesmo direito, na escola, de negociar os sentidos e significados e os caminhos que lhe permitem construir conhecimento.

\section{Referências}

AGUIAR, W. M. J.; OZELLA, S. Núcleos de significação como instrumento para apreensão da constituição de sentidos. Psicologia: Ciência e profissão. Brasília, v.26, n.2, p. 222-245, jun. 2006. Disponivel em: https://doi.org/10.1590/S141498932006000200006. Acesso em 15 de janeiro de 2019.

AGUIAR, W. M. J.; OZELLA, S. Apreensão de sentidos: aprimorando a proposta dos núcleos de significação. Revista Brasileira de Estudos Pedagógicos. Brasília, v. 94, n.236, p. 299-322, jan./abr. 2013. Disponível em:

https://www.scielo.br/j/rbeped/a/Y7jvCHjksZMXBrNJkqq4zjP/abstract/?lang=pt\#. Acesso em 22 de novembro de 2018.

ASSOCIAÇÃO NACIONAL DOS SURDOS. Revista do I.N.S.M. Rio de Janeiro: I.N.S.M., n. 2, 1949. Disponível em: http://repositorio.ines.gov.br/ilustra/handle/123456789/378. Acesso em 14 maio 2020.

BAKHTIN, M. Estética da criação verbal. São Paulo, Martins Fontes: [1953] 1992.

BRASIL. Decreto 5626, de 22 de setembro de 2005. Regulamenta a Lei 10.436, de 24 de abril de 2002, que dispõe sobre a Língua Brasileira de Sinais e o art. 18 da Lei 10.098, de 19 de dezembro de 2000. Diário Oficial da União. Brasília, 2005. Disponível em: http://www.planalto.gov.br/ccivil_03/_ato20042006/2005/decreto/d5626.htm. Acesso em: 1 maio 2017.

BRASIL. Lei 10.436 de 24 de abril de 2002. Dispõe sobre a Língua Brasileira de Sinais. Diário Oficial da União. Brasília, 2002. Disponível em: http://www.planalto.gov.br/ccivil_03/leis/2002/110436.htm. Acesso em: 1 maio 2017.

BRONCKART, J. P. Atividade de linguagem, texto e discursos: por um interacionismo sócio-discursivo. São Paulo: EDUC, 1999.

DORZIAT, A. Metodologias específicas ao ensino de surdos. Programa de Capacitação de Recursos Humanos do Ensino Fundamental Deficiência Auditiva, Brasília, v. I, n.4, p. 299-308, 1997. 
FELIPE, T. A. Libras em contexto curso básico: Livro do Estudante. $8^{\mathrm{a}} \mathrm{ed}$. Rio de Janeiro: Walprint gráfica e Editora, 2007.

FIDALGO, S. S. A linguagem da inclusão/exclusão-Escolar na história, nas leis e na prática educacional. Tese (Doutorado em Linguística Aplicada e Estudos da Linguagem) - Pontifícia Universidade Católica - PUC/SP, São Paulo, 2006.

FIDALGO, S. S. A Linguagem da Exclusão e da Inclusão Social na Escola. São Paulo: Editora Unifesp, 2018.

FREITAS, M. M. Ensino-aprendizagem de aspectos da língua portuguesa para surdos com experiência acadêmica: um estudo à luz da pesquisa crítica de colaboração. Orientadora: Sueli Salles Fidalgo. 2020. 218 f. Tese (Doutorado em Educação e Saúde na Infancia e na Adolescencia) Universidade Federal de São Paulo, Guarulhos, 2020.

GIORDANI, L. F. Encontros e desencontros da língua escrita. In: LODI, A. C. B.; MÉLO, A. D. B.; FERNANDES, E. Letramento, Bilinguismo e Educação de Surdos. Porto Alegre: Editora Mediação, 2015, p. 135 - 152.

GÓES, M. C. R. Linguagem, surdez e educação. Campinas: Autores Associados, 1996.

KOCH, I. G. V. Desvendando os segredos do Texto. $7^{\mathrm{a}}$ ed. São Paulo: Cortez, 2011.

LODI, A. C. B.; MELO, A. D. B.; FERNANDES, E. Letramento, bilinguismo e educação de surdos. Porto Alegre: Mediação, 2015.

MAGALHÃES, M. C. C. Etnografia colaborativa e desenvolvimento do professor. In: Trabalhos de Linguistica Aplicada. Campinas, n. 23, p. 71-78, jan/ jun 1994.

MAGALHÃES, M. C. C. Por uma Prática Crítica de Formação Contínua de Educadores. In: FIDALGO, S. S.; SHIMOURA, A. S. Pesquisa crítica de colaboração: Um percurso na formação docente. São Paulo: Ductor, 2006. p. 94-103.

MAGALHÃES, M. C. C.; FIDALGO, S. S. Reviewing Critical Research Methodologies for Teacher Education in Applied Linguistics. Delta, V. 35, n. 3, 2019.

MOURA, D. R. Libras e Leitura de Língua Portuguesa para Surdos. Curitiba: Appris, 2015.

PEREIRA, M. C. C. Leitura, escrita e surdez. 2. ed. São Paulo: FDE, 2009.

PEREIRA, M. C. C. Ensino da Língua Portuguesa para Surdos. Acervo Digital da Unesp. [entre 2014 e 2019] Disponível em:

https://acervodigital.unesp.br/bitstream/unesp/252175/1/unesp -

nead_reei1_ee_d11_da_texto1.pdf. Acesso em: 20 abr. 2019. 
PINHEIRO, L. M. A “inclusão” escolar de alunos surdos: colaborações para pensar as adaptações curriculares. Curitiba: Appris, 2020.

SÃO PAULO. Secretaria Municipal de Educação. Coordenadoria Pedagógica. Currículo da cidade: Educação especial: Língua Portuguesa para surdos. São Paulo: SME / COPED, 2019.

SCHÖN, D. A. Formar professores como profissionais reflexivos. In: NÓVOA, A. Os professores e sua formação. Lisboa: Dom Quixote, 1992.

SKLIAR, C. (org.). Atualidade da educação bilíngue para surdos. Porto Alegre: Mediação, 1999.

SMYTH, J. Teachers Work and the Politics of Reflection. American Educational Research Journal Summer, [S. 1]. v. 29, n. 2, p. 267-300, 1992.

SOFIATO, C. G.; LEÃO, G. B. O. S. O uso da Iconografia/imagem na educação de surdos: diálogos possíveis. XVII Endipe - Encontro Nacional de Didática e Prática de Ensino. Universidade Estadual do Ceará - Publicado no EdUEce, Livro 3, 2014.

SOUZA, R. M. Intuições "Linguísticas" sobre a Língua de Sinais nos séculos XVIII e XIX, a partir da compreensão de dois escritores surdos da época. Revista D.E.L.T.A., São Paulo, v. 19, n.2, p. 329-344, 2003.

VIEIRA, C. R. Bilinguismo e Inclusão: Problematizando a questão. Curitiba: Appris, 2014.

VIEIRA, C. R. Educação bilíngue para surdos: Reflexões a partir de uma Experiência Pedagógica. Orientadora: Karina Soledad Maldonado Molina Pagnez. 2017. 236 f. Tese (Doutorado em Educação). Faculdade de Educação, Universidade de São Paulo, São Paulo, 2017.

VYGOTSKY, L. S. A formação social da mente. São Paulo: Martins Fontes, [1930] 1998.

VYGOTSKY, L. S. A construção do pensamento e da linguagem. São Paulo: Martins Fontes, [1934] 2001 (Tradução de Paulo Bezerra).

VYGOTSKY, L. S.; LURIA, A. R.; LEONTIEV, A. N. Linguagem, desenvolvimento e Aprendizagem. São Paulo: Ícone, [1933] 1998. 